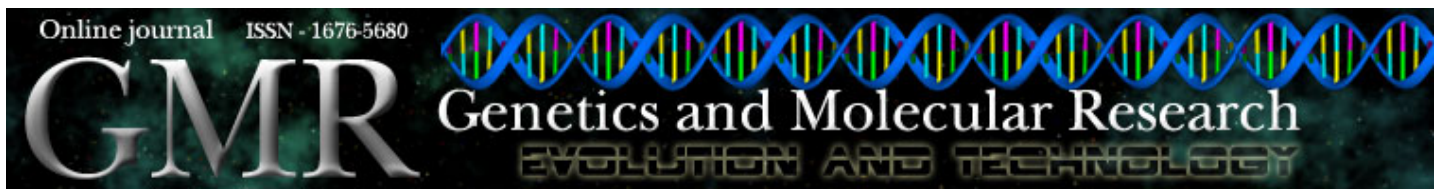

Review Article

\title{
Size of beef cows: early ideas, new developments
}

\author{
Jesus A. Arango ${ }^{1}$ and L. Dale Van Vleck ${ }^{2}$ \\ ${ }^{1}$ University of Nebraska, Lincoln, ${ }^{2}$ USDA, ARS, Roman L. Hruska U.S. \\ Meat Animal Research Center, Lincoln, NE 68583-0908, USA \\ The current address of J.A. Arango is Facultad de Ciencias Veterinarias, \\ Universidad Central de Venezuela, Apartado. 4563, Maracay 2101, Aragua, \\ Venezuela \\ Corresponding author: L.D. Van Vleck. A218 Animal Sciences, University \\ of Nebraska, Lincoln 68583-0908, Fax: 402/472-6362 \\ E-mail: dvan-vleck1@unl.edu
}

Key words: Beef cattle, Optimal size, Efficiency of growth, Longitudinal data, Covariance functions, Random regression models

Genet. Mol. Res. 1 (1): 51-63 (2002)

Received February 8, 2002

Published March 10, 2002

\section{INTRODUCTION}

Optimum size for beef cattle is debated among researchers, cattle breeders and producers. Cattle vary widely in body size but optimal size depends on the production system. Selection has placed emphasis on growth, favoring leaner and faster growing cattle. This trend has led to an increase in mature size of cattle that may not necessarily be advantageous. Many research results have indicated that there is not a direct relationship between size and efficiency in beef production if each biological type of cattle is managed according to its nutrient requirements for maximum reproduction and growth. Considering the wide diversity of environments and management practices within the beef industry in the world, however, a careful choice of the breed or cross is required to maximize efficiency for each situation.

Beef cattle have a low rate of reproduction and a high maternal cost per animal marketed. Therefore, the two most important components that determine efficiency of beef cows are milk production and mature body weight (Dickerson, 1970; McMorris and Wilton, 1986; MontañoBermudez et al., 1990). Although most genetic evaluation programs of beef cattle report Expected Progeny Differences (EPD) for maternal ability for weaning weight, only one in the United States currently reports EPD for mature size (Wilson, 2000).

The importance of body size to efficiency has led to traits associated with size, mass and dimension (such as mature weight, mature height and other body measurements) being 
included in selection programs and being included in breeding objectives for crossbreeding plans.

The expression of body size can be represented by a set of size-age points that gradually change until reaching a plateau at maturity. These points represent a typical longitudinal process resulting in a set of many, highly correlated measures. The challenge is how to condense the array of data points for an animal into a manageable set of parameters with biological meaning. Several approaches have been proposed to deal with growth data, ranging from the simplest repeatability model to the full multivariate model. At one extreme, the repeatability model considers growth at different stages as realizations of the same genetic trait with constant parameters. At the other extreme, each measurement of an age-size point is considered to be a different trait (multivariate approach). Intermediate alternatives include the traditional "growth functions", which explain the growth trajectory using a small set of parameters defined by a deterministic equation. Growth curves have been a standard way to evaluate growth. More recent approaches to the study of longitudinal data, such as growth, have been use of covariance functions and random regression models. Under this framework, infinite-dimensional models have been proposed where the phenotype of an individual is represented by a continuous function of time, which is not restricted to a predefined growth equation. This approach offers great flexibility for handling data from a diverse range of ages.

This review will cover general aspects of growth with special emphasis on size and efficiency of beef cows. Approaches used to evaluate adult growth, including traditional growth equations and the more recent covariance functions and random regression models, will be discussed.

\section{REVIEW OF LITERATURE}

The increase in size, number or mass with time is the primary definition of growth but does not include the phenomenology and etiology of growth, such as the energy transactions in the growing animal in terms of the processes of metabolism, nutrition and genetics (Parks, 1982). Growth includes not only increase of body size per se, but also biological phenomena at the cellular level in terms of increase in the number (hypertrophy), and size (hyperplasia) of cells and in changes of form and chemical composition resulting from differential growth of different components of the body, especially muscle and fat (Berg and Butterfield, 1976). Growth is continuous during an animal's life, from zygote formation until the adult stage (mature weight), and therefore, should be evaluated by growth rate or by weight and size increases during different stages of life. Tentative classes of growth would include: 1) prenatal growth, 2) preweaning growth, 3) postweaning growth, and 4) mature size. The interest here is in the last class.

Body growth is determined by genetic and non-genetic factors. The genetic make up of the individual includes additive and non-additive genetic combinations that determine growth. These combinations interact with environmental conditions such as climate, nutrition, and management and intrinsic factors such as sex, age, physiological status, as well as other extrinsic factors such as maternal effects and random environmental factors to determine the ultimate phenotypic expression of growth.

Even though growth is variable among individuals, growth follows a well-defined course in populations of animals as the age (Parks, 1982). Growth generally follows a sigmoid or S-shaped curve through which the rate of growth varies with age until the rate slowly declines to zero reaching a plateau when the animal achieves mature weight. 
Cattle vary widely in body size, with optimum mature weight for lifetime production differing importantly among breeds (Brown et al., 1989; Johnson et al., 1990). Optimal cow size depends on the production system (Morris and Wilton, 1976, 1977; Andersen, 1978; Dickerson, 1978; Fitzhugh, 1978; Notter et al., 1979). The biological type implies different nutrient requirements for maximum reproduction and growth and to achieve market weight for optimum efficiency of meat production. Each type should be evaluated under management and market conditions for which it is best suited (Dickerson, 1978). Andersen (1978) postulated that there are no general relationships between size of cattle and economic and biological efficiency, and that optimal size will depend on market demands, and especially on climatic environment and husbandry practices.

Efficiency of growth is more important in cattle than other meat animals because of the low rate of reproduction and high maternal maintenance cost per animal marketed. In general, within breed, efficiency is associated with different measurements of body size. Milk production also is a vital component of efficiency (Dickerson, 1970). For example, differences in milk production explained $23 \%$ of the variation in maintenance requirements when beef cows of different breed composition were fed to maintain constant body weight (MontañoBermudez et al., 1990). Positive relationships between growth rate and mature size with milk yield have been reported in cattle (Andersen, 1978). Body size can have both biological and economic effects on the efficiency of production. The main components of efficiency in beef cattle have been defined (Morris and Wilton, 1975, 1976, 1977; Andersen, 1978; Dickerson, 1978; Fitzhugh, 1978; Notter et al., 1979). The proportion of total energy intake required solely for body maintenance is over $50 \%$ in adult cattle and represents the most important factor that determines biological efficiency; the maintenance overhead. Ferrell and Jenkins (1985) concluded that about three-fourths of the energy requirement for a life cycle is needed for maintenance but that requirements for maintenance vary more than requirements for growth, gestation and lactation. Larger mature size, however, implies greater weight at birth and puberty, and more gain at late ages (Dickerson, 1970; Jeffery and Berg, 1972; Laster et al., 1976, Southgate et al., 1982; McMorris and Wilton, 1986; Petit and Lienard, 1988; Humes and Munyakazi, 1989; Cundiff et al., 1993; Fiss and Wilton, 1993), longer gestation and lactation lengths (Taylor, 1973; Andersen, 1978; McMorris and Wilton, 1986; Fiss and Wilton, 1989), greater lean to fat ratio (Cundiff et al., 1986; Humes and Munyakazi, 1989), and heavier market weights and more days on feed for steers (Southgate et al., 1982; McMorris and Wilton, 1986), but little difference in feed conversion to similar market finish or proportion of mature size (Smith et al., 1976a; McMorris and Wilton, 1986; Fiss and Wilton, 1993). However, some of the biological components interact in different ways for different body sizes. Breeds selected for milk production reach puberty earlier than breeds of similar mature size and lean growth potential that do not have a history of selection for milk production (Cundiff et al., 1993). On the other hand, biological types with high milk production potential, medium to large body size, and relatively high reproduction rates, require a favorable nutrient environment to meet requirements for growth, lactation and maintenance, as was the case for some breed groups evaluated in the Germ Plasm Evaluation Project at the Meat Animal Research Center (Cundiff et al., 1986). In a simulation study, Brinks and Miller (1990) found that when feed resources were not limited, large cows with a high level of milk production and low management-labor requirements showed optimum net return. However, in a nutritionally stressful Australian environment, small (fertile) cows were more efficient, rearing calves of similar weight as heavy (lowly fertile) cows (Seifert and Rudder, 1975). Brinks and Bourdon (1993) defined mating systems to match biological type of cow (mature size and milk production) to feed resources for the cow herd (high to low). They suggested that large or high milking cows should be 
avoided if feed resources are limited. However, they also indicated that there is more flexibility for choice of cow size-milk level with a high level of feed resources (Brinks and Bourdon, 1993).

Adaptation is another important component of biological efficiency. Body size has an important effect on the way animals respond to climate, feed resources, seasonal influences and marketing strategies. Large body size may have advantages under cold stress and in use of abundant food supply, but marketing would be at older ages (Dickerson, 1978). On the other hand, animals with smaller body size are more efficient for grazing under seasonal and scarce forage resources (Taylor et al., 1972) and show better adaptation to hot and dry climates. Under harsh environments there seems to have been natural selection for small mature size (Fitzhugh, 1978). Small animals also mature, reach market weight and reproduce at earlier ages than larger ones (Dickerson, 1978).

Genetic origin has also been identified as having an important effect on efficiency. Research has shown substantial advantages of Bos indicus-Bos taurus crosses over Bos taurus crossbred cows for efficiency in the Germplasm Evaluation Program at the US-Meat Animal Research Center (Cundiff et al., 1983; Green et al., 1991a,b). Zebu crosses benefit from a greater level of heterosis for milk production, feed utilization and longevity. Bos indicus cattle also seem to have superior longevity for maternal performance. Heat stress in the summer environment of Nebraska may have a factor favoring the more heat tolerant Bos indicus crosses in those experiments (Green et al., 1991a).

Economic effects of body size include, fixed cost per animal, inflexible body size standards and feed costs for breeding and growing animals (Dickerson, 1978). The effect of body size on economic variables has been defined for a wide variety of beef cattle genotypes (Morris and Wilton, 1975, 1977; McMorris et al., 1986).

The complex interactions among biological and economic components of efficiency preclude assigning effects of mature size per se to life-cycle biological efficiency of meat production when young animals of each type are marketed at the body weight that maximizes total feed efficiency for dam and market animal (Morris and Wilton, 1977; Dickerson, 1978). Genetic improvement of cow-herd productivity has emphasized increase in weights of leaner progeny for marketing at specific times in the production cycle (Notter et al., 1979; Humes and Munyakazi, 1989). However, animals with larger mature weight have greater maintenance costs, so that increased body size is generally not considered desirable for the breeding herd (Fiss and Wilton, 1992). A negative relationship of cow size with productivity but a positive one with rate of maturing has been reported for crossbred (Marshall et al., 1984; Humes and Munyakazi, 1989) and purebred beef cattle (Morrow et al., 1978; Lopez de la Torre et al., 1992). Dickerson (1978) indicated that body size per se is of little importance in determining efficiency when compared with functional output per unit of body size in reproduction, growth and body composition. Fitzhugh (1978) also concluded that when system inputs and outputs are proportional to size, no general relationship between size of breeding female and production efficiency would be expected. However, constraints of size for some genotypes may lead to important size of genotype $\mathrm{x}$ production environment interactions. With simulation, Lamb et al. (1992) found that cow weight accounted for only $6 \%$ of variation in predicted biological efficiency. Notter et al. (1979) concluded that mature body size was not important to efficiency for a midwestern cow-calf-feedlot system if feed quality and quantity were not limiting, and if the degree of maturity at weaning and slaughter was the same for all breeds. Some advantages were found for large types if feed quality and voluntary intake varied seasonally.

No breed excels in all traits that are important. With respect to efficiency, the objective is more lean growth and earlier sexual maturity with minimum increase in mature weight 
(Dickerson, 1970). The "productive approach" to body size postulated by Dickerson (1970, 1978) includes: 1) choosing the mature body size best adapted to the environmental, breeding system and market factors for the area of production, and 2) focusing primarily on improvement of functional components of performance such as: reproduction rate, relative growth and body composition. Breeding methods can be used to maximize efficiency over a set of environmental conditions. Selection of promising breeds and crossbreeding combinations, crossing sires of best growth and carcass breeds with dam breeds or crosses, which are superior for female production and reproduction, would be advantageous (Dickerson, 1970).

The importance of body size to efficiency has led to defining variables associated with mature weight of breeding animals. Mature weight derived from actual adult weight measurements and/or by fitting growth curves (i.e., asymptotic weight), as well as time or rate variables (e.g., rate of maturity, percentage of mature weight attained at a given age and metabolic age) associated with mature weight have been used.

Mature weight is often referred to as ' $A$ ' which signifies adult weight or asymptotic weight in growth curve studies. Adult weight is interpreted as average size at maturity independent of short-term fluctuations in size due to extraneous environmental effects of climate and food supply (Fitzhugh, 1976). Therefore, adult weight is usually chosen to represent genetic body size (Taylor, 1985). Maturity is the only period in the life of an animal when the growth is normally in an unchanging state. Other definitions of mature weight depend on the nature of the study. When ' $\mathrm{A}$ ' is obtained from actual measurements of adult weight, mature weight has been defined as "the average of about three repeated weights taken annually both in the spring and the fall" (Brinks et al., 1964). MacNeil et al. (1984) defined mature weight as the average of four weights of 7-year-old cows taken in different seasons. When derived from growth curves, 'A' begins to be reliable only when data extend beyond 4.5 years (Morrow et al., 1978; Johnson et al., 1990, 1991). Because prediction can be affected by temporal environmental variation and with inclusion of data up to 6.5 years, 'A' should be an estimate of mature size which is free from seasonal fluctuations (Kaps et al., 1999). Smith et al. (1976a) defined mature weight as fat-constant, asymptotic weight at 6 to 9 years of age adjusted for body condition score. Johnson et al. (1990) referring to previous studies of Brody and Taylor, considered animals to be fully mature when they had attained $98 \%$ of their asymptotic weight. Bullock et al. (1993) defined mature weight as the average of all weights taken on the animal after it stops growing. For practical purposes, they used the closest weight after the inflection point (1506 days in their data) as mature weight. Kaps et al. (1999) included only cows having weights at five years of age or later for their analysis of mature weight.

Some studies of nutrition and breed efficiency have required more precise definition of mature weight. Taylor (1985) defined mature weight as "the body weight of a normally grown, skeletally mature, normally active adult animal maintained in a state of body weight equilibrium on a standard diet, in a thermoneutral, disease-free environment with, or adjusted to, a chemical body fat of $20 \%$ ". However, practical definitions do not require such a degree of sophistication.

Ideally, prediction of mature weight should be based on all available information; however, mature weight can also be predicted from immature body weight and/or other measures of body size. The use of weights of contemporary animals reared under the same environment also increases the accuracy of prediction (Taylor, 1985).

Longitudinal data represent records of traits changing, usually gradually but continuously, over time. Fitzhugh Jr. (1976) defined longitudinal data as a complete set of measurements available for every individual at every age (stage). The expression of body size or growth is described by a set of size-age (representing weights, heights, etc.) points that change until 
reaching a plateau at maturity. They represent a typical longitudinal process and result in a set of many, typically highly correlated measurements (Meyer, 1998a). The problem with using such data is how to condense the array of data points for an animal into a unique (or small set) of parameter (s) with biological meaning.

Several approaches have been proposed to deal with growth data. The most simplistic model assumes that different weights of the same animal represent the same trait with constant variance during the animal's life. The so-called 'repeatability model' considers sequential weights of an animal as repeated measurements of a single trait. Another approach is to consider measurements at different ages as separate traits that are genetically correlated, with heterogeneous variances, and treat them with a 'multivariate model'. One problem with this approach is that it requires arbitrary subdivision of age segments to represent different traits.

A widely used approach has been to fit growth data with mathematical functions or 'growth curve equations'. Those functions, known as 'biologically based curves' (Sandland and McGilchrist, 1979), are based on deterministic differential equations that seek a biological interpretation. A large number of such functions were developed in the last fifty years trying to best describe the complex growth of animals in terms of a few parameters that are both mathematically efficient and biologically interpretable. This approach avoids the hazards of independently interpreting a large number of weight-age points that are subject to temporary environmental effects, errors of measurement and random environmental influences (Fitzhugh Jr., 1976; Johnson et al., 1990). Fitting a curve with sufficient data for each individual would be expected to smooth out the random deviations.

The many equations that have been used to predict growth for cattle include Gompertz, Robertson's logistic, Brody, Bertalanfy, Feller, Weiss and Kavanau, Fitzhugh, Richards, Laird, and Parks equations. Summarized descriptions can be found in Parks (1982). The most used to describe growth patterns in beef cattle are: Brody, Bertalanfy, logistic, Gompertz and Richards (Brown et al., 1976; Fitzhugh Jr., 1976; Johnson et al., 1990). All are special cases of the general Richards growth function, a nonlinear, four parameter model defined as

$$
\mathrm{W}_{\mathrm{t}}=\mathrm{A}\left(1-\mathrm{be}^{-\mathrm{kt}}\right)^{\mathrm{m}}
$$

where $\mathrm{A}$ is asymptotic (mature) weight, $\mathrm{b}$ is a time scale parameter, $\mathrm{k}$ is rate of approach to mature weight, $\mathrm{t}$ is age and $\mathrm{m}$ is a shape parameter that allows for a variable inflection point. The special cases differ in the number of parameters. The Richards' equation allows $m$ to vary to account for an inflexion point but the others treat $\mathrm{m}$ as a given fixed constant. Several studies have compared these curves for cattle (Brown et al., 1976; Fitzhugh Jr., 1976; DeNise and Brinks, 1985; Johnson et al., 1990; Lopez de la Torre et al., 1992; Mezzadra and Miquel, 1994). DeNise and Brinks (1985) and Beltran et al. (1992) compared Brody and Richards' equations.

The Brody equation has been the most used in beef cattle studies because it is easy to compute and interpret and allows for missing data points, and because of goodness of fit (Brown et al., 1972; Nelsen et al., 1982; Stewart and Martin, 1983; Johnson et al., 1990, 1991; Beltran et al., 1992; Bullock et al., 1993; Kaps et al., 1999). In some studies Richards' function was reported to fit data better than the Brody equation (DeNise and Brinks, 1985; Beltran et al., 1992; Lopez de la Torre, 1992) or other Richards' functions (Mezzadra and Miquel, 1994). Other studies have used the Richards' function as the equation of choice (Morrow et al., 1978; Mezzadra and Miquel, 1994; Peroto et al., 1997). The Gompertz equation has been reported as showing less bias for estimation of 'A' (Lopez de la Torre et al., 1992) and has been the function of choice in some studies (Pitchford et al, 1993; Meyer, 1995; Archer et al., 1998). The Bertalanfy 
function was concluded to be the most appropriate in a study that compared various functions (Lopez de la Torre et al., 1992).

Fitzhugh and Taylor (1971) proposed an equation-free method to examine genetic differences in degree of maturity in which the mean growth curve did not need to be fitted. The method requires a previous estimate of mature size and is based on the relationship: $\mathrm{y}_{t}=\mathrm{Au}_{\mathrm{t}}$ where $y_{t}$ is a measurement of weight at a given stage of development (y), A is the usual mature weight and $u_{t}$ is the proportion of mature size attained at given age $(t)$. The logarithmic form, $\ln y_{t}=\ln A+\ln u_{t}$ (Fitzhugh Jr., 1976; Johnson et al., 1990), is convenient and easy to compute. Useful growth statistics can be derived from the method such as: average absolute growth rate (AGR), average absolute maturing rate (AMR) and their relative counterparts (RGR and RMR). This method is advantageous for irregular data and has been applied to beef cow weights (Smith et al., 1976a,b).

Genetically standardized growth equations have also been proposed (Taylor, 1980, 1985) to facilitate comparison of species and breeds differing in body size through genetic size-scaling evaluation. Taylor introduced the concept of metabolic age as a counterpart to degree of maturity in traditional growth functions.

Segmented regression procedures have also been used to fit growth data, in attempts to overcome some weaknesses of traditional growth functions. Warren et al. (1980) described the method for segmented line regression, and explained it with an example using data from Polled Hereford females.

Most of the growth models have been fitted by ordinary least squares, which seems to be inefficient because of the strong dependence structure within the growth process (Sandland and McGilchrist, 1979). Improved versions of the traditional growth functions have allowed data for each animal to be fitted individually and for estimation of parameters for the Brody equation (Doren et al., 1989; Kaps et al., 1999), the quadratic regression function with plateau (Bullock et al., 1993) and the Gompertz function (Pitchford et al, 1993; Meyer, 1995; Archer et al., 1998). This approach allows analyses within the context of the mixed model approach using restricted maximum likelihood techniques as described by Meyer (1995) and Kaps et al. (1999).

At extremes of the age range, usual approaches for genetic analysis of longitudinal measurements of growth do not seem adequate either because they do not account for the intrinsic variability of the process (repeatability models) or they lead to overparameterized models with a large number of parameters, which are difficult to interpret and which do not account for ordering and spacing of the records over time (Meyer and Hill, 1997; Meyer, 1998c). The growth curves impose artificial mathematical constraints on the biological variation inherent to growth (Johnson et al., 1990). They also restrict the relationship of size and age to a deterministic equation in which all animals share the same growth pattern (same curve shape), and do not always account for the complexity of the process. For example, most growth curves assume that growth is a monotonic increasing function on time, which is not very realistic. Fitted curves also smooth irregularities of the actual data, but problems of interpretation occur when the irregularities substantially affect estimates of the parameters. Some adjustment options have been difficult to implement or have led to bias in the parameter estimates (Fitzhugh Jr., 1976).

A recent approach to deal with trajectory or longitudinal data, such as growth, has been proposed using covariance functions, CF (Kirkpatrick and Heckman, 1989; Kirkpatrick et al., 1990, 1994; Meyer and Hill, 1997). Potentially infinite, highly correlated, measures over time for an individual may comprise longitudinal data. Under this framework, infinitedimensional models have been proposed where the phenotype of an individual is represented 
by a continuous function of time. The CF is defined to quantify variation of the growth trajectories about the mean, which is equivalent to the covariance matrix in the finite-dimensional model (Kirkpatrick and Heckman, 1989; Kirkpatrick et al., 1990). The CF models, in contrast to growth curves, are based on stochastic processes and define the covariance between any two records measured at given ages as a function of the ages and some basic coefficients. The family of orthogonal polynomials (e.g., Legendre polynomials) is often chosen as suitable functions to represent coefficients for the CF model. Such polynomials have been the basis of statistical growth curve models (Wishart, 1938; Rao, 1965; Grizzle and Allen, 1969; Sandland and McGilchrist, 1979) and are the coefficients most widely used to describe size-age relationships in animals (Fitzhugh Jr., 1976). Other suitable functions include segmented polynomials, such as spline functions (e.g., Meyer, 1998b; Gilmour et al., 1999), and sine and cosine functions as approximations to Fourier series (Meyer, 1999b).

The CF model offers three advantages over the conventional approach (Kirkpatrick and Heckman, 1989). First, the CF model can be used to predict the full growth trajectory (rather than at only landmark ages) without making assumptions about the families of curves that are possible. Second, the CF leads to more correct prediction of response to selection because the model takes into account the effect of selection at all points over the trajectory. Third, CF models seem to reduce bias in estimates of genetic variation. In addition, CF models account for spacing of the ages at which data are collected (Kirkpatrick et al., 1990).

The model in theory allows an infinite number of coefficients to be used to describe the CF, but in practice a limited number of coefficients (designated, the order of fit) can be used to estimate the covariance structure. If the order of fit equals the number of unique ages in the data the $\mathrm{CF}$ approach is equivalent to a full multivariate analysis (in the finite-dimensional framework). However, the objective is to find a parsimonious model with a minimum number of parameters to adequately describe the data. A reduced order of fit usually explains the data. A smaller order of fit reduces the number of parameters to estimate, and at the same time results in a smooth surface representing the full covariance matrix.

A generalized least squares method was used to estimate the coefficients of a CF from a given covariance matrix (Kirkpatrick et al., 1990) and was illustrated with lactation yield in dairy cattle (Kirkpatrick et al., 1994). However, the method requires that estimates of the matrix of covariances among records at the ' $t$ ' observed ages are available. That requirement makes Kirpatrick's method computationally expensive, especially for big data sets. Meyer and Hill (1997) developed an alternative method to estimate CF coefficients directly from the data using REML. They proposed a reparameterization of existing algorithms used for the finitedimensional approach based on derivative-free search (Meyer, 1991) or derivative based procedures using the 'average information' matrix (Meyer and Smith, 1996). The method was not computationally demanding for the simplest case of an animal model with a balanced design. However, for the general case with missing values, the method is computationally demanding. The computational load is proportional to ' $t$ ', the number of ages in the data.

An equivalent procedure to obtain CF was proposed originally as random regression models, RRM (Henderson Jr., 1982; Laird and Ware, 1982; Jennrich and Schluter, 1986). Schaeffer and Dekkers (1994) and Jamrozik and Schaeffer (1997) redefined it for test-day production in dairy cattle as a procedure similar to the maternal genetic effect model with the difference that in the RRM the design matrix contains coefficients different from zero or one. The model allows fitting coefficients for parts of the functions of days-in-milk (DIM) for each cow as random variables. Estimates of breeding values with RRM represent prediction of differences in both shape and height of the lactation curve, which would also allow for genetic evaluation for persistency. They concluded that the inclusion of random genetic components 
of regression in animal models may be applicable to any situation of time-dependent variables represented by functions exhibiting genetic variation, such as growth. The main requirement for the model is that the time-dependent response can be expressed as a linear function of a set of covariates (Schaeffer and Dekkers, 1994). The equivalence between CF and RRM has been described (Meyer, 1998a; van der Werf et al., 1998; Schaeffer, 1999).

Meyer (1998a,c) refined the RRM, implemented computer software (Meyer, 1998b,d), and described analyses of mature weight in beef cattle (Meyer, 1998a, 1999a,b). She showed the equivalence between the CF models and the RRM when fitting polynomials of age as independent variables, and showed that REML estimates of the coefficients of CF can be obtained as covariances among the regression coefficients. The order of the mixed model equations of the procedure to estimate $\mathrm{CF}$ with RRM is proportional to the order of fit of the regression coefficients and not to the ages measured in the data as shown by Meyer and Hill (1997). This procedure offers considerably more flexibility for handling data coming in 'at all ages' and should be especially advantageous for reduced rank of fit (Meyer, 1998a). The DxMRR software for RRM (Meyer, 1998b,d) fits coefficients of Legendre polynomials as a default, allows for reduced order of fit and rank, and provides estimates of genetic as well as permanent environmental animal effects. Corresponding covariance functions for the additive genetic $(A)$ and permanent environmental $(R)$ effects are then estimated. Heterogeneity of temporary environment variances, corresponding, for example, to ages represented in the data, is also accommodated.

Functions other than orthogonal 'Legendre' polynomials have been proposed as suitable for the RRM approach such as segmented polynomials or spline functions (Gilmour et al., 1999; Meyer, 1999b), and sine and cosine functions as approximations to Fourier series (Meyer, 1999b).

Applications of RRM to growth and related traits include papers by Andersen and Pedersen (1996) in pigs, and Koenen et al. (1999) and Jones et al. (1999) for live weight and live-weight changes, and condition score in dairy cattle, respectively. In beef cattle the method was outlined by Varona et al. (1997), and was used by Meyer (1998a, 1999a,b, 2000) and by Arango (2000).

\section{CONCLUSIONS AND IMPLICATIONS}

Breeds and crosses for beef production vary widely in body size. Considering the wide diversity of environments and management practices within the beef industry in the world, careful choice of the breed or cross must be practiced in each case to obtain cow size to maximize efficiency.

Beef production is characterized by use of many breeds representing broad biological diversity for economic traits. This fact provides flexibility for matching genotypes to particular managerial and environmental situations. To optimize body size in terms of productivity Dickerson $(1970,1978)$ recommended: 1) selection for mature size best adapted to the environment, breeding system and market factors of the area of production, and 2) focus primarily on improvement of functional components of performance such as reproduction, relative growth and body composition.

Traits associated with size have been recommended to be included in selection programs and as breeding objectives in crossbreeding plans. Size-related traits represent examples of longitudinal data. Statistical methods are available to analyze longitudinal data using the traditional growth curves and the more recently covariance functions and random regression 
models.

Rate of genetic change from selection for adult size (weight or height) may be affected by relatively late expression and measurement of the traits. Use of records taken early in life would decrease the generation interval and because of high genetic correlations among weights and size measurements at different ages would seem reasonable to be used (Jenkins et al., 1991; Bullock et al., 1993; Northcutt and Wilson, 1993; Meyer, 1995; Kaps et al., 1999). Measures of early maturing traits, such as height, taken at early ages might be used in multiple trait approaches to select indirectly for optimal adult weight.

\section{REFERENCES}

Andersen, B.B. (1978). Animal size and efficiency, with special reference to growth and feed conversion in cattle. Anim. Prod. 27: 381-391.

Andersen, S. and Pedersen, B. (1996). Growth and food intake curves for group-housed gilts and castrated male pigs. Anim. Sci. 63: 457-464.

Arango, J.A. (2000). Genetic study of weight, height and body condition score in beef cows. Ph.D. Dissertation, University of Nebraska-Lincoln, NE., USA.

Archer, J.A., Herd, R.M., Arthur, P.F. and Parnell, P.F. (1998). Correlated responses in rate of maturation and mature size of cows and steers to divergent selection for yearling growth rate in Angus cattle. Livest. Prod. Sci. 54: 183-192.

Beltran, J.J., Butts Jr., W.T., Olson, T.A. and Koger, M. (1992). Growth patterns of two lines of Angus cattle selected using predicted growth parameters. J. Anim. Sci. 70: 734-741.

Berg, R.T. and Butterfield, R.M. (1976). New Concepts of Cattle Growth. John Wiley and Sons, New York, NY, USA, pp. 240.

Brinks, J.S. and Bourdon, R. (1993). Matching cattle to resources and fine-tuning the breeding program. In: Proceedings of Matching Beef Cattle to Western Environments, Phoenix, AZ, USA, pp. 122-137.

Brinks, J.S. and Miller, W.C. (1990). Optimizing cow size, milk level and labor by computer modeling. In: Proc. West. Sec. Am. Anim. Sci. 41: 152-155.

Brinks, J.S., Clark, R.T., Kieffer, N.M. and Urick, J.J. (1964). Estimates of genetic, environmental and phenotypic parameters in range Hereford females. J. Anim. Sci. 23: 711-716.

Brown, C.J., Johnson, Z.B. and Brown Jr., A.H. (1989). Between and within breed variation in mature weight and maturing interval of beef cattle. J. Anim. Sci. 67 (Suppl. 2): 9 (Abstract).

Brown, J.E., Brown, C.J. and Butts, W.T. (1972). A discussion on the genetic aspects of weight, mature weight and rate of maturing in Hereford and Angus cattle. J. Anim. Sci. 34: 525-537.

Brown, J.E., Fitzhugh Jr., H.A. and Cartwright, T.C. (1976). A comparison of nonlinear models for describing weightage relationships in cattle. J. Anim. Sci. 42: 810-818.

Bullock, K.D., Bertrand, J.K. and Benyshek, L.L. (1993). Genetic and environmental parameters for mature weight and other growth measures in Polled Hereford cattle. J. Anim. Sci. 71: 1737-1741.

Cundiff, L.V., Ferrell, C.L. and Jenkins, T.G. (1983). Output/input differences among F $_{1}$ cows of diverse biological type. J. Anim. Sci. 57 (Suppl. 1): 148 (Abstract).

Cundiff, L.V., Gregory, K.E., Koch, R.M. and Dickerson, G.E. (1986). Genetic diversity among cattle breeds and its use to increase beef production efficiency in a temperate environment. In: 3rd World Congress on Genetics Applied to Livestock Production (Johnson, R.K. and Dickerson, G.E., eds.). Lincoln, NE, USA, IX: 271-282.

Cundiff, L.V., Szabo, F., Gregory, K.E., Koch, R.M., Dikeman, M.E. and Crouse, J.D. (1993). Breed comparisons in the germplasm evaluation program at MARC. Presented at the Beef Improvement Federation 25th Anniversary Conference, Asheville, NC, USA, pp. 13.

DeNise, R.S.K. and Brinks, J.S. (1985). Genetic and environmental aspects of the growth curve parameters in beef cows. J. Anim. Sci. 61: 1431-1440.

Dickerson, G.E. (1970). Efficiency in animal production - molding the biological components. J. Anim. Sci. 30: 849-859.

Dickerson, G.E. (1978). Animal size and efficiency: basic concepts. Anim. Prod. 27: 367-379.

Doren, P.E., Baker, J.F., Long, C.R. and Cartwright, T.C. (1989). Estimating parameters of growth curves of bulls. J. Anim. Sci. 67: 1432-1445.

Ferrell, C.L. and Jenkins, T.G. (1985). Cow type and the nutritional environment: Nutritional aspects. J. Anim. Sci. 61: 725-741.

Fiss, C.F. and. Wilton, J.W. (1989). Effects of breeding system, cow weight and milk yield on reproductive performance in beef cattle. J. Anim. Sci. 67: 1714-1721.

Fiss, C.F. and Wilton, J.W. (1992). Contribution of breed, cow weight and milk yield to the traits of heifers and cows in four breeding systems. J. Anim. Sci. 70: 3686-3696.

Fiss, C.F. and Wilton, J.W. (1993). Contribution of breed, cow weight and milk yield to the preweaning, feedlot, and carcass traits of calves in three beef breeding systems. J. Anim. Sci. 71: 2874-2884.

Genetics and Molecular Research 1 (1): 51-63 (2002) www.funpecrp.com.br 
Fitzhugh, H.A. (1978). Animal size and efficiency, with special reference to the breeding female. Anim. Prod. 27: 393-401. Fitzhugh, H.A. and Taylor St., C.S. (1971). Genetic analysis of degree of maturity. J. Anim. Sci. 33: 717-725.

Fitzhugh Jr., H.A. (1976). Analysis of growth curves and strategies for altering their shape. J. Anim. Sci. 42: 1036-1051.

Gilmour, A.R., Cullis, B.R. and Welham, S.J. (1999). ASREML Reference Manual, pp. 210. Available at: fttp:// ftp.res.bbrsc.ac.uk/pub/aar/. Accessed Nov. 15, 1999.

Green, R.D., Cundiff, L.V., Dickerson, G.E. and Jenkins, T.G. (1991a). Output/input among nonpregnant, lactating Bos indicus-Bos taurus and Bos taurus-Bos taurus $\mathrm{F}_{1}$ cross cows. J. Anim. Sci. 69: 3156-3166.

Green, R.D., Cundiff, L.V. and Dickerson, G.E. (1991b). Life-cycle biological efficiency of Bos indicus-Bos taurus and Bos taurus crossbred cow-calf production to weaning. J. Anim. Sci. 69: 3544-3563.

Grizzle, J.E. and Allen, D.M. (1969). Analysis of growth and dose response curves. Biometrics 25: 357-381.

Henderson Jr., C.R. (1982). Analysis of covariance in the mixed model: higher-level, nonhomogeneous, and random regression. Biometrics 38: 623-640.

Humes, P.E. and Munyakazi, L. (1989). Size and production relationship in crossbred beef cattle. Louisiana Agric. 33: 12-13.

Jamrozik, J. and Schaeffer, L.R. (1997). Estimates of genetic parameters for test-day model with random regression for yield traits of first lactating Holsteins. J. Dairy Sci. 80: 762-770.

Jeffery, H.B. and Berg, R.T. (1972). An evaluation of several measurements of beef cow size as related to progeny performance. Can. J. Anim. Sci. 52: 23-37.

Jenkins, T.G., Kaps, M., Cundiff, L.V. and Ferrell, C.L. (1991). Evaluation of between and within-breed variation in measures of weight-age relationships. J. Anim. Sci. 69: 3118-3128.

Jennrich, R.I. and Schluter, M.D. (1986). Unbalanced repeated-measure models with structured covariance matrices. Biometrics 42: 805-820.

Johnson, Z.B., Brown, C.J. and Brown Jr., A.H. (1990). Evaluation of growth patterns of beef cattle. Arkansas Agric. Exp. Stn. Bull. No. 923, pp. 41.

Johnson, Z.B., Brown, C.J. and Brown Jr., A.H. (1991). Optimum beef cow size for production resources in Northern Arkansas. Arkansas Agric. Exp. Stn. Spec. Rep. 151: 43-47.

Jones, H.E., White, I.M.S. and Brotherstone, S. (1999). Genetic evaluation of Holstein Friesian sires for daughter condition-score changes using a random regression model. J. Anim. Sci. 68: 467-475.

Kaps, M., Herring, W.O. and Lamberson, W.R. (1999). Genetic and environmental parameters for mature weight in Angus cattle. J. Anim. Sci. 77: 569-574.

Kirkpatrick, M. and Heckman, N. (1989). A quantitative genetic model for growth, shape, reaction norms, and other infinite-dimensional characters. J. Math. Biol. 27: 429-450.

Kirkpatrick, M., Lofsvold, D. and Bulmer, M. (1990). Analysis of the inheritance and evolution of growth trajectories. Genetics 124: 979-993.

Kirkpatrick, M., Hill, W.G. and Thompson, R. (1994). Estimating the covariance structure of traits during growth and aging, illustrated with lactation in dairy cattle. Genet. Res. 64: 57-69.

Koenen, E.P.C., Groen, A.F. and Gengler, N. (1999). Phenotypic variation in live weight and live-weight changes of lactation Holstein-Friesian cows. J. Anim. Sci. 68: 109-114.

Laird, N.M. and Ware, J.H. (1982). Random-effects model for longitudinal data. Biometrics 38: 963-974.

Lamb, M.A., Tess, M.W. and Robison, O. (1992). Evaluation of mating systems involving five breeds for integrated beef production systems: I. Cow-calf segment. J. Anim. Sci. 70: 689-699.

Laster, D.B., Smith, G.M. and Gregory K.E. (1976). Characterization of biological types of cattle. IV. Postweaning growth and puberty of heifers. J. Anim. Sci. 43: 63-70.

Lopez de la Torre, G., Candotti, J.J., Reverter, A., Bellido, M.M., Vasco, P., Garcia, L.J. and Brinks, J.S. (1992) Effects of growth parameters on cow efficiency. J. Anim. Sci. 70: 2668-2672.

MacNeil, M.D., Cundiff, L.V., Dinkel, C.A. and Koch, R.M. (1984). Genetic correlations among sex-limited traits in beef cattle. J. Anim. Sci. 58: 1171-1180.

Marshall, T.E., Mohler, M.A. and Stewart, T.S. (1984). Relationship of lifetime productivity with mature weight and maturation rate in Red Poll cows. Anim. Prod. 39: 383-387.

McMorris, M.R. and Wilton, J.W. (1986). Breeding system, cow weight and milk yield effects on various biological variables in beef production. J. Anim. Sci. 63: 1361-1372.

McMorris, M.R., Wilton, J.W. and Pfeiffer, W.C. (1986). Breeding system, cow weight and milk yield effects on various economic variables in beef production. J. Anim. Sci. 63: 1373-1383.

Meyer, K. (1991). Estimating variances and covariances for multivariate animal models by restricted maximum likelihood. Genet. Sel. Evol. 23: 67-83.

Meyer, K. (1995). Estimates of genetic parameters for mature weight of Australian beef cows and its relationship to early growth and skeletal measures. Livest. Prod. Sci. 44: 125-137.

Meyer, K. (1998a). Estimating covariance functions for longitudinal data using a random regression model. Genet. Sel. Evol. 30: 221-240.

Meyer, K. (1998b). 'DxMRR' - A program to estimate covariance functions for longitudinal data by Restricted Maximum Likelihood. In: Proceedings of the 6th World Congress on Genetics Applied to Livestock Production, Armidale, Australia 27: 465-466.

Meyer, K. (1998c). Modeling 'repeated' records: Covariance functions and random regression models to analyze animal breeding data. In: Proceedings of the 6th World Congress on Genetics Applied to Livestock Production, Armidale, 
Australia 27: 517-520.

Meyer, K. (1998d). DFREML - version 3.0 B - User Notes (Mimeo), pp. 29. Available at: ftp://metz.une.edu.au/pub/ agbu/DFREML. Accessed Sept. 30, 1999.

Meyer, K. (1999a). Estimates of genetic and phenotypic covariance functions for postweaning growth and mature weight of beef cows. J. Anim. Breed. Genet. 116: 181-205.

Meyer, K. (1999b). Random regression to model phenotypic variation in monthly weights of Australian beef cows (Mimeo) 19 pp + Tables and Graphics. Available at: ftp://agbu.une.edu.au/ kmeyer/. Accessed Sept. 30, 1999.

Meyer, K. (2000). Random regression to model phenotypic variation in monthly weights of Australian beef cows. Livest. Prod. Sci. 65: 19-38. Also available at: ftp://metz.une.edu.au/pub/agbu/Papers/phnrrm.ps.gz. Accessed May 16, 2000.

Meyer, K. and Hill, W.G. (1997). Estimation of genetic and phenotypic covariance functions for longitudinal or 'repeated' records by restricted maximum likelihood. Livest. Prod. Sci. 47: 185-200.

Meyer, K. and Smith, S.P. (1996). Restricted maximum likelihood estimation for animal models using derivatives of the likelihood. Genet. Sel. Evol. 28: 23-49.

Mezzadra, C.A. and Miquel, M.C. (1994). Heterosis and breed transmitted effects in growth curve parameters in Angus, Criollo and reciprocal crossbred cows. In: Proceedings of the 5th World Congress on Genetic Applied to Livestock Production (Smith, C., Gavora, J.S., Benkel, B., Chesnais, J., Fairfull, W., Gibson, J.P., Kennedy, B.W. and Burnside, E.B., eds.). Guelph, Canada 17: 276-279.

Montaño-Bermudez, M., Nielsen, M.K. and Deutscher, G.H. (1990). Energy requirements for maintenance of crossbred beef cattle with different genetic potential for milk. J. Anim. Sci. 68: 2279-2288.

Morris, C.A. and Wilton, J.W. (1975). Influence of mature cow weight on economic efficiency of cows. Can. J. Anim. Sci. 55: 233-250.

Morris C.A. and Wilton, J.W. (1976). The influence of body size on the biological efficiency of cows: A review. Can. J. Anim. Sci. 56: 613-647.

Morris C.A. and Wilton, J.W. (1977). The influence of body size on the economic efficiency of cows: A review. Anim. Breed. Abstr. 45: 139-153.

Morrow, R.E., McLaren, J.B. and Butts, W.T. (1978). Effect of age on estimates of bovine growth curve parameters. J. Anim. Sci. 47: 352-357.

Nelsen, T.C., Long, C.R. and Cartwright, T.C. (1982). Postinflection growth in straightbred and crossbred cattle. I. Heterosis for weight, height and maturing rate. J. Anim. Sci. 55: 2280-2292.

Northcutt, S.L. and Wilson, D.E. (1993). Genetic parameters and expected progeny differences for mature size in Angus cattle. J. Anim. Sci. 71: 1148-1153.

Notter, D.R., Sanders, J.O. and Dickerson, G.E. (1979). Simulated efficiency of beef production for a Midwestern cowcalf-feedlot management system. II. Mature body size. J. Anim. Sci. 49: 83-91.

Parks, J.R. (1982). A Theory of Feeding and Growth of Animals. Springer-Verlag, Berlin, Germany, pp. 322.

Peroto, D., Castanho, M.J. de P., Cubas, A.C., Rocha, J.L. and Pinto, J.M. (1997). Efeitos genéticos sobre as estimativas dos parâmetros das curvas de crescimento de fêmeas bovinas Gir, Guzera, Holandes x Gir e Holandes x Guzera. Rev. Bras. Zoot. 26: 719-725.

Petit, M. and Lienard, G. (1988). Performance characteristics and efficiency of various types of beef cows in French production system. In: 3rd World Congress of Sheep and Beef Cattle Breeding. Paris, France 2: 25-51.

Pitchford, W.S., Barlow, R. and Hearnshaw, H. (1993). Growth and calving performance of cows from crosses between the Brahman and Hereford. Livest. Prod. Sci. 33: 141-150.

Rao, C.R. (1965). The theory of the least squares when the parameters are stochastic and its application to the analysis of growth curves. Biometrika 52: 447-458.

Sandland, R.L. and McGilchrist, C.A. (1979). Stochastic growth curve analysis. Biometrics 35: 255-271.

Schaeffer, L.R. (1999). Random regression models. Class Notes, pp. 20. Available at: http://www.aps.uoguelph.ca/ 1rs/ animalz/lesson 14/Accessed Nov. 21, 2000.

Schaeffer, L.R. and Dekkers, J.C.M. (1994). Random regression in animal models for test-day production in dairy cattle. In: Proceedings of the 5th World Congress on Genetic Applied to Livestock Production (Smith, C., Gavora, J .S., Benkel, B., Chesnais, J., Fairfull, W., Gibson, J.P., Kennedy, B.W. and Burnside, E.B., eds.). Guelph, Canada 18: 443-446.

Seifert, G.W. and Rudder, T.H. (1975). The genetic implications of selecting cattle for large size. In: Principles of Cattle Production (Swan, H. and Broster, W.H., eds.). Butterworths \& Co. Ltd., London, UK., pp. 373-386.

Smith, G.M., Fitzhugh Jr., H.A., Cundiff, L.V., Cartwright, T.C. and Gregory, K.E. (1976a). A genetic analysis of maturing patterns in straightbred and crossbred Hereford, Angus and Shorthorn cattle. J. Anim. Sci. 43: 389-395.

Smith, G.M., Fitzhugh Jr., H.A., Cundiff, L.V., Cartwright, T.C. and Gregory, K.E. (1976b). Heterosis for maturing weight patterns in Hereford, Angus and Shorthorn cattle. J. Anim. Sci. 43: 380-388.

Southgate, J.R., Cook, G.L. and Kempster, A.J. (1982). A comparison among different breed and crosses from the suckler herd. Anim. Prod. 35: 87-98.

Stewart, T.S. and Martin, T.G. (1983). Optimal mature size of Angus cows for maximum cow productivity. Anim. Prod. 37: 179-182.

Taylor, C.R., Caldwell, S.L. and Rowntree, V.J. (1972). Running up and down hills. Some consequences of size. Science 178: 1096-1097.

Taylor St., C.S. (1973). Genetic differences in milk production in relation with mature body weight. Proc. Br. Soc. 
Anim. Prod. (New Series) 2: 15-26.

Taylor St., C.S. (1980). Genetically standardized growth equations. Anim. Prod. 30: 1167-1175.

Taylor St., C.S. (1985). Use of genetic size-scaling in evaluation of animal growth. J. Anim. Sci. 61 (Suppl. 2): 118-143. van der Werf, J.H.J., Goddard, M.E. and Meyer, K. (1998). The use of covariance functions and random regression for genetic evaluation of milk production. J. Dairy Sci. 81: 3300-3308.

Varona, L., Moreno, C., Garcia-Cortes, L.A. and Altarriba, J. (1997). Multiple trait genetic analysis of underlying biological variables of production functions. Livest. Prod. Sci. 47: 201-210.

Warren, J.H., Schalles, R.R. and Milliken, G. (1980). A segmented line regression procedure to describe growth in beef cows. Growth 44: 160-166.

Wilson, D.E. (2000). Angus mature cow size genetic evaluation. In: 2000 Angus Sire Evaluation. American Angus Association. Available at: http://www.ccp.com./ angus/sireeval/mature.htm. Accessed February 15, 2000.

Wishart, J. (1938). Growth-rate determinations in nutrition studies with the bacon pig and their analysis. Biometrics 30: $16-28$. 